\title{
Modelagem farmacocinética/farmacodinâmica do florfenicol para o tratamento da adenite equina por meio da simulação de Monte Carlo*
}

\section{Pharmacokinetic/pharmacodynamic modeling of florfenicol for the treatment of equine adenitis using Monte Carlo simulation}

\author{
Emanuely Ramos Tameirão, ${ }^{* *}$ Pedro Henrique Alves de Faria, ${ }^{* * *}$ Lucas Wamser Fonseca Gonzaga, ${ }^{* *}$ \\ João Vitor Fernandes Cotrim de Almeida, ${ }^{* * * *}$ Ticiana Meireles Sousa, ${ }^{* * * * *}$ Humberto de Mello Brandão, ${ }^{* * * * *}$ \\ Marcos Ferrante ******
}

\begin{abstract}
Resumo
O objetivo deste trabalho foi avaliar a eficácia do florfenicol na dose usualmente empregada em equinos de $22 \mathrm{mg} / \mathrm{kg}$ pelas vias intravenosa, intramuscular e oral para o tratamento de adenite equina por Streptococcus equi. subsp. equi, usando a modelagem farmacocinética/farmacodinâmica (PK/PD - Pharmacokinetic/Pharmacodynamic) e a simulação de Monte Carlo. Foi realizada uma simulação de Monte Carlo a partir dos parâmetros PK, logo depois, efetuou-se a modelagem PK/PD para determinar as taxas de eficácia do antimicrobiano para o tratamento dessa infecção bacteriana, de acordo com o valor da concentração inibitória mínima (CIM), em um intervalo de CIM de 0,125 - $4 \mu \mathrm{g} / \mathrm{mL}$. Pela via intravenosa, a probabilidade de erradicação bacteriana foi de $100 \%$ para CIM até $0,5 \mu \mathrm{g} / \mathrm{mL}$ e efeito bacteriostático com probabilidades de $99 \%$ e $80 \%$ para CIMs de 2 e $4 \mu \mathrm{g} / \mathrm{mL}$, respectivamente. Já pelas vias intramuscular e oral a probabilidade de se atingir o índice de erradicação bacteriológica foi de $100 \%$ para CIM de até $0,5 \mu \mathrm{g} / \mathrm{mL}$, contudo, atinge valores de $80 \%$ e $81 \%$, respectivamente, para CIM de $1 \mu \mathrm{g} / \mathrm{mL}$ considerando o efeito bactericida $(p<0,01)$. Portanto, através desse estudo é evidenciado a eficácia do florfenicol até a CIM de $0,5 \mu \mathrm{g} / \mathrm{mL} \mathrm{para}$ as três vias de administração citadas, entretanto, para CIMs superiores a esse valor, é imprescindível o ajuste da dose farmacológica, evitando falhas na terapêutica e possível resistência microbiana.
\end{abstract}

Palavras-chave: Antibioticoterapia, garrotilho, infecção bacteriana, medicina individualizada.

\begin{abstract}
The objective of this study was to evaluate the efficacy of florfenicol at the dose usually used in horses of $22 \mathrm{mg} / \mathrm{kg}$ by intravenous, intramuscular and oral routes for the treatment of equine adenitis caused by Streptococcus equi. subsp. equi, using Pharmacokinetic/ Pharmacodynamic (PK/PD) modeling and Monte Carlo simulation. A Monte Carlo simulation was performed from the PK parameters, then PK/PD modeling was performed to determine the antimicrobial efficacy rates for the treatment of this bacterial infection, according to the minimum inhibitory concentration (MIC) value, in a MIC range of $0.125-4 \mu \mathrm{g} / \mathrm{mL}$. Intravenously, the probability of bacterial eradication was $100 \%$ for MICs up to $0.5 \mu \mathrm{g} / \mathrm{mL}$, and the bacteriostatic effect was $99 \%$ and $80 \%$ for MICs of 2 and 4 $\mu \mathrm{g} / \mathrm{mL}$, respectively. However, for the intramuscular and oral routes, the probability of reaching the bacteriologic eradication index was $100 \%$ for MICs of up to $0.5 \mu \mathrm{g} / \mathrm{mL}$, however, it reaches values of $80 \%$ and $81 \%$, respectively, for MICs of $1 \mu \mathrm{g} / \mathrm{mL}$ considering the bactericidal effect $(p<0.01)$. Therefore, through this study the efficacy of florfenicol is evidenced up to the MIC of $0.5 \mu \mathrm{g} / \mathrm{mL}$ for the three routes of administration cited, however, for MICs higher than this value, it is essential to adjust the pharmacological dose, avoiding failures in therapy and possible microbial resistance.
\end{abstract}

Keywords: Antibiotic therapy, bacterial infection, garrotilho, individualized medicine.

\footnotetext{
*Recebido em 6 de março de 2021 e aceito em 11 de maio de 2021.

**Universidade Federal de Lavras, Faculdade de Zootecnia e Medicina Veterinária, Lavras, MG, Brasil

*** Médico Veterinário Autônomo

****Universidade Federal Lavras, Faculdade de Zootecnia e Medicina Veterinária, Programa de Pós-Graduação Ciências Veterinárias (Fisiologia e Metabolismo Animal), Lavras, MG, Brasil

*****Universidade Federal de Lavras, Faculdade de Zootecnia e Medicina Veterinária, Departamento de Clínica Médica de Grandes Animais, Lavras, MG, Brasil

****** Pesquisador Embrapa Gado de Leite, Juiz de Fora, MG, Brasil.

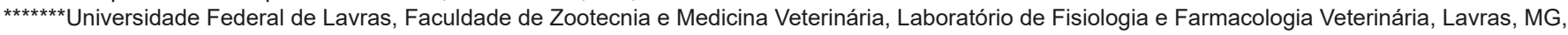
Brasil. *E-mail: marcos.ferrante@ufla.br
} 


\section{Introdução}

O rebanho de equinos brasileiro é o maior da América Latina e o terceiro no mundo, com total de 5,85 milhões de cavalos, gerando empregos diretos e indiretos para o país (IBGE, 2019). Nesse contexto, torna-se imprescindível o controle sanitário dos rebanhos, já que as enfermidades associadas à equideocultura brasileira, leva a grandes prejuízos (GOMES et al., 2019).

Das enfermidades que mais acometem a espécie, destacam-se àquelas do sistema respiratório, tendo como a mais representativa a adenite equina, popularmente conhecida como garrotilho. É uma doença bacteriana, causada por Streptococcus equi subsp. equi, cocos gram positivos, beta-hemolíticos do grupo C de Lancefield (LIBARDONI, 2015). A doença se caracteriza por um processo inflamatório mucopurulento do trato respiratório superior de equinos, manifestado por corrimento, tosse, febre, anorexia, depressão e abscesso de linfonodos (FLOCK et al., 2012).

O tratamento dessa infecção inclui a antibioticoterapia, todavia, esse tratamento pode ser dificultado pela resistência de cepas de $S$. equi aos antimicrobianos (ALONSO et al., 2019). Para isso, surgiram as ferramentas de modelagem farmacocinética/farmacodinâmica (PK/PD - Pharmacokineticl Pharmacodynamic), que atualmente são usadas na medicina veterinária como um recurso para testar a eficiência dos agentes antibacterianos antes mesmo do tratamento clínico (TRANG et al., 2017).

A modelagem PK/PD junto com a simulação de Monte Carlo permitem que, por meio de uma técnica matemática que utiliza uma amostragem aleatória repetida, caracterize as probabilidades de alcançar os alvos PK/PD não-clínicos adequado entre pacientes simulados, favorecendo o estabelecimento da dose terapêutica para o tratamento da infecção, por meio do conhecimento das concentrações inibitórias mínimas (CIMs) bacterianas e seus respectivos efeitos, promovendo, assim, a erradicação da bactéria, reduzindo o risco de ineficácia terapêutica e o avanço da resistência bacteriana (FERRANTE, 2018).

O objetivo deste trabalho foi avaliar a eficácia do florfenicol na dose usualmente empregada em equinos de $22 \mathrm{mg} / \mathrm{kg}$ pelas vias intravenosa, intramuscular e oral para o tratamento de adenite equina, usando a modelagem PK/PD e a simulação de Monte Carlo.

\section{Material e métodos}

Para avaliar a eficácia do florfenicol foram seguidas as orientações contidas no "Guideline on the use of pharmacokinetics and pharmacodynamics in the development of antimicrobial medicinal products" da Agência Europeia de Medicamentos (EMA, 2016). A eficácia do florfenicol foi analisada considerando as vias de administração oral, intramuscular e intravenosa, na dose usualmente empregada em equinos de $22 \mathrm{mg} / \mathrm{kg}$, segundo as concentrações inibitórias mínimas (CIMs) da bactéria causadora da adenite equina, Streptococcus equi. subsp. equi no intervalo de 0,125 - $4 \mu \mathrm{g} / \mathrm{mL}$. Para isso, foram empregados os parâmetros farmacocinéticos (PK) obtidos no estudo de Mckellar e Varma (1996), que foi realizado em equinos $(n=6)$, sendo determinados os valores da área sob a curva (ASC) no período de $0-24 \mathrm{~h}$ das concentrações plasmáticas de 64,16 \pm 9,62 $\mu \mathrm{g} \mathrm{h} / \mathrm{mL}, 52,02$ $\pm 0,25 \mu \mathrm{g} \mathrm{h} / \mathrm{mL}, 53,45 \pm 0,17 \mu \mathrm{g} \mathrm{h} / \mathrm{mL}$ pelas vias intravenosa, intramuscular e oral, respectivamente (Figura 1).

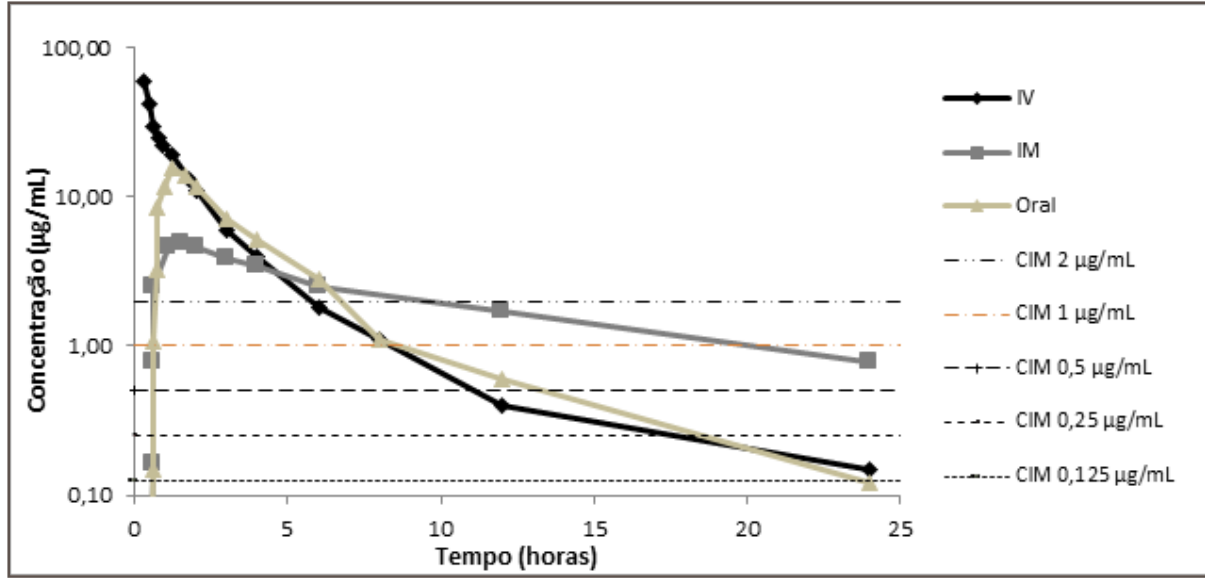

Figura 1:- Concentração plasmática em função do tempo após a administração de florfenicol na dose de $22 \mathrm{mg} / \mathrm{kg}$ por via intravenosa (IV), intramuscular (IM) e oral (VO) em equinos e as concentrações inibitórias mínimas (CIM) das bactérias infectantes. (Adaptado de Mckellar e Varma, 1996). valores para uma população de 10.000 indivíduos de acordo com a simulação de Monte Carlo (ODA, 2011; SHARMA et al., 2016). Posteriormente, foi avaliada a eficácia para cada indivíduo tomando como parâmetro os índices farmacocinéticos/ farmacodinâmicos (PK/PD) da ASC da concentração plasmática em função do tempo (0 - $24 \mathrm{~h})$, pela concentração inibitória mínima $\left(\mathrm{ASC}_{24} / \mathrm{ClM}_{90}\right)$ demonstrados na Tabela 1.

O efeito antibacteriano da dose de $22 \mathrm{mg} / \mathrm{kg}$ de florfenicol foi determinado de acordo com as ações bacteriostática, bactericida e de erradicação bacteriológica, ou seja, quando a redução bacteriana é maior que $4 \log _{10}$. Os índices de $\mathrm{ASC}_{24} / \mathrm{CIM}_{90}$ foram 14, 43 e 63 para efeito bacteriostático, bactericida e de erradicação bacteriológica, respectivamente. Esses valores foram obtidos a partir do gráfico de curva de morte bacteriana realizada no trabalho de Dorey et al. 2017 e independem da via de administração do fármaco.

A simulação de Monte Carlo foi realizada usando os parâmetros de ASC no programa Excel (ODA, 2011; SHARMA et al., 2016). Já a análise estatística, nos programas Excel e BioEstat 5.0. Todas as taxas de eficácia foram comparadas, de acordo com cada CIM estudada, mediante o teste de independência do QuiQuadrado com uma significância de $(p<0,01)$.

\section{Resultado e discussão}

No presente trabalho foi possível estimar, através da simulação, a eficácia da dose de $22 \mathrm{mg} / \mathrm{kg}$ de florfenicol, pelas vias IV, IM e VO para o tratamento de adenite equina, considerando as 
probabilidades de se atingir o efeito desejado em diferentes concentrações de susceptibilidade bacterianas.

Tabela 1: Parâmetros farmacocinéticos (PK) e farmacocinéticos/ farmacodinâmicos (PK/PD) do florfenicol, sendo o parâmetro PK correspondente a área sob a curva de tempo de concentração plasmática de $0-24 \mathrm{~h}\left(\mathrm{ASC}_{0-24 \mathrm{~h}}\right) \mathrm{e}$ o PK/PD correspondente a $\mathrm{ASC}_{0-24 h}$ pela concentração inibitória mínima bacteriana $\left(\mathrm{ASC}_{0-24 \mathrm{~h}} / \mathrm{CIM}_{90}\right)$

\begin{tabular}{lccc}
\hline Parâmetros & IV & IM & Oral \\
\hline $\mathrm{ASC}_{0-24 \mathrm{~h}}(\mathrm{mg} \cdot \mathrm{h} / \mathrm{mL})$ & $64 \pm 9$ & $52 \pm 8$ & $53 \pm 8$ \\
$\mathrm{ASC}_{0-24 \mathrm{~h}} / \mathrm{CIM}_{90} 0,25$ & $256 \pm 39$ & $208 \pm 32$ & $214 \pm 32$ \\
$\mathrm{ASC}_{0-24 \mathrm{~h}} / \mathrm{CIM}_{90} 0,5$ & $128 \pm 19$ & $104 \pm 16$ & $207 \pm 16$ \\
$\mathrm{ASC}_{0-24 \mathrm{~h}} / \mathrm{CIM}_{90} 1$ & $64 \pm 10$ & $52 \pm 8$ & $53 \pm 8$ \\
$\mathrm{ASC}_{0-24 \mathrm{~h}} / \mathrm{CIM}_{90} 2$ & $32 \pm 5$ & $26 \pm 4$ & $27 \pm 4$ \\
$\mathrm{ASC}_{0-24 \mathrm{~h}} / \mathrm{CIM}_{90} 4$ & $16 \pm 2$ & $13 \pm 2$ & $13 \pm 2$ \\
\hline
\end{tabular}

Considerando a via intravenosa, para bactérias com CIM até $0,5 \mu \mathrm{g} / \mathrm{mL}$ há $100 \%$ de probabilidade de se obter a erradicação bacteriológica, diminuindo para $51 \%$ para bactérias com CIM de $1 \mu \mathrm{g} / \mathrm{mL}$ e $0 \%$ para CIMs maiores que $1 \mu \mathrm{g} / \mathrm{ml}$. Entretanto, há uma probabilidade de efeito bacteriostático alta de $99 \%$ e $80 \%$ para bactérias com CIMs de 2 e $4 \mu \mathrm{g} / \mathrm{ml}$, respectivamente. E por último, o efeito bactericida máximo foi de $48 \%$ para bactérias com CIM de $1 \mu \mathrm{g} / \mathrm{mL}$ (Figura 2).

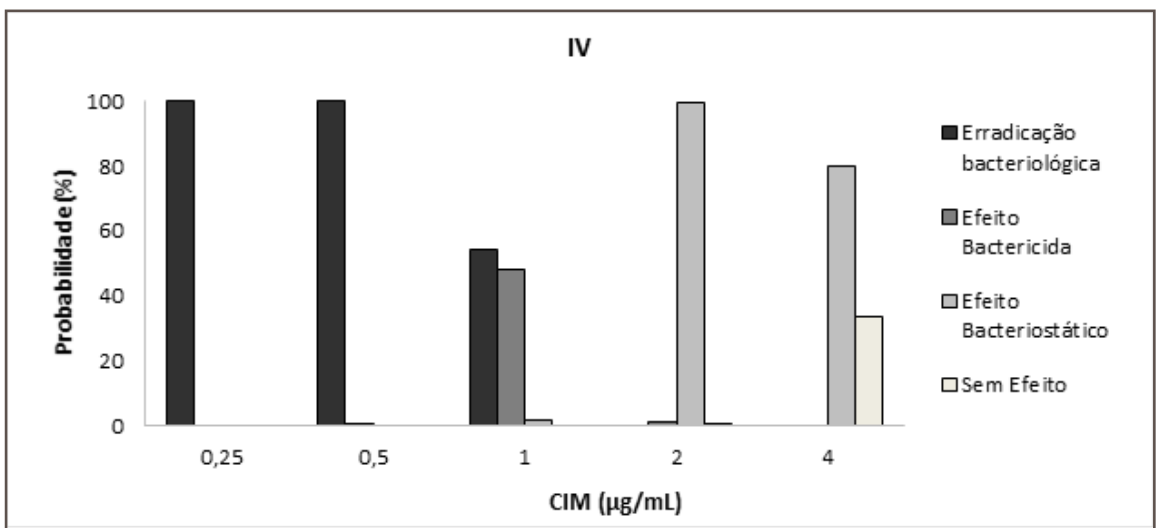

Figura 2: Probabilidade de atingir o índice ASC24/CIM de acordo com a CIM após tratamento com 22 $\mathrm{mg} / \mathrm{kg}$ de florfenicol em equinos por via intravenosa baseado na simulação de Monte Carlo $(n=10.000)$.

Comparativamente, os resultados demonstraram que após a administração de $22 \mathrm{mg} / \mathrm{kg}$ de florfenicol pela via intramuscular os efeitos bacteriostáticos e, principalmente, bactericidas, foram mais eficientes, apresentando probabilidades maiores obter o sucesso terapêutico que pela via intravenosa. $(p<0,01)$. Para bactérias com CIM de até $0,5 \mu \mathrm{g} / \mathrm{ml}$ a probabilidade de se obter a erradicação bacteriológica foi de $100 \%$, diminuindo consideravelmente para CIMs acima desse valor. Já para as bactérias com CIM de 1, 2 e $4 \mu \mathrm{g} / \mathrm{ml}$ apresentaram 16\%, 100\% e $31 \%$ de efeito bacteriostático, respectivamente. Por fim, bactérias com CIM de $1 \mu \mathrm{g} / \mathrm{ml}$ apresentaram efeito bactericida de $80 \%$. (Figura 3).
Ainda, os resultados da administração por via oral evidenciam que para bactérias com CIM de até $0,5 \mu \mathrm{g} / \mathrm{ml}$ a probabilidade de se obter a erradicação bacteriológica foi de $100 \%$, com decréscimo da probabilidade acima da CIM de 0,5 $\mu \mathrm{g} / \mathrm{ml}$. Para as bactérias com CIM de 1, 2 e $4 \mu \mathrm{g} / \mathrm{ml}$ apresentaram $12 \%, 100 \%$ e $38 \%$ de efeito bacteriostático, respectivamente e as bactérias com CIM de $1 \mu \mathrm{g} / \mathrm{ml}$ também apresentaram efeito bactericida de $81 \%$. (Figura 4 ).

Figura 04 - Probabilidade de atingir o índice ASC24/CIM de acordo com a CIM após tratamento com $22 \mathrm{mg} / \mathrm{kg}$ de florfenicol em equinos por via oral baseado na simulação de Monte Carlo ( $n=10.000)$.

De acordo com os resultados, a dose de $22 \mathrm{mg} / \mathrm{kg}$ de florfenicol nas três vias de administração IV, IM e VO apresentam taxas de eficácia para o tratamento de infecções por S. equi variáveis dependente das CIMs da bactéria e da ação desejada. Comparando as taxas de eficácia das três vias, a administração IV foi a que apresentou melhor efeito de erradicação bacteriológica frente às CIMs entre $0,25-1 \mu \mathrm{g} / \mathrm{ml}$, como esperado, porém, essa apresenta maior dificuldade de aplicação para o tratamento em condições a campo. Já considerando o efeito bactericida, as vias IM e VO atingem taxas eficazes frente a CIM de $1 \mu \mathrm{g} / \mathrm{ml}$. Então, estimar as doses adequadas para a aplicação por via intramuscular ou oral para CIMs superiores, permitiria o uso do antimicrobiano com maior eficácia e praticidade.

A partir dos dados deste trabalho é possível evidenciar como as diferenças na farmacocinética entre as três vias de administração impactam na eficácia do tratamento. Outro fato a ser considerado é a necessidade que haja concentração suficiente do antimicrobiano no sítio da infecção; a soma destes fatores determinará o sucesso da antibioterapia (AHMAD et al., 2016; TOUTAIN et al., 2020).

Os modelos PK/PD são mecanismos que permitem, a partir dos parâmetros farmacocinéticos/farmacodinâmicos, predizer os valores de ASC/CIM indicando se o antimicrobiano será eficaz para o tratamento em função das CIMs bacterianas (LUO et al., 2019). Em conjunto, o modelo PK/PD com a simulação de Monte Carlo, que leva em consideração todas as variáveis PK e PD importantes que afetam o resultado bacteriológico, permitem determinar a dosagem do antimicrobiano para uso clínico.

O índice PK/PD adequado do florfenicol é determinado pela a área sob a curva de tempo de concentração plasmática de 0 a 24 horas $\left(\mathrm{ASC}_{0-24 \mathrm{~h}}\right.$ ), sobre a $\mathrm{CIM}$ dos microrganismos infectantes ( $\mathrm{ASC}_{0-24 \mathrm{~h}} / \mathrm{CIM}$ ) (DOREY et al., 2017; MARTíN et al., 2019; XIAO et al., 2021). Além disso, a abordagem PK/PD Monte Carlo estabelece três níveis de eliminação bacteriana, bacteriostática, bactericida e erradicação bacteriológica, como em um estudo feito por Dorey et al. (2017) para dois microrganismos causadores de pneumonia em suínos, Actinobacillus pleuropneumoniae e Pasteurella multocida, minimizando erros evitáveis na terapia in vivo.

Apesar dessas vantagens claras, existem limitações inevitáveis 


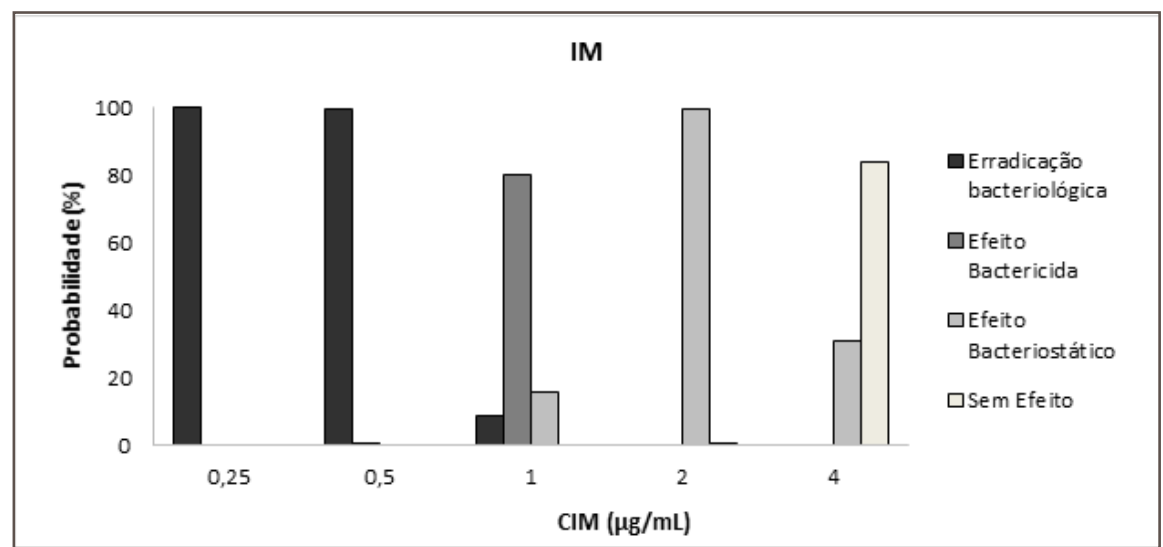

Figura 3: Probabilidade de atingir o índice ASC24/CIM de acordo com a CIM após tratamento com $22 \mathrm{mg} / \mathrm{kg}$ de florfenicol em equinos por via intramuscular baseado na simulação de Monte Carlo $(n=10.000)$.

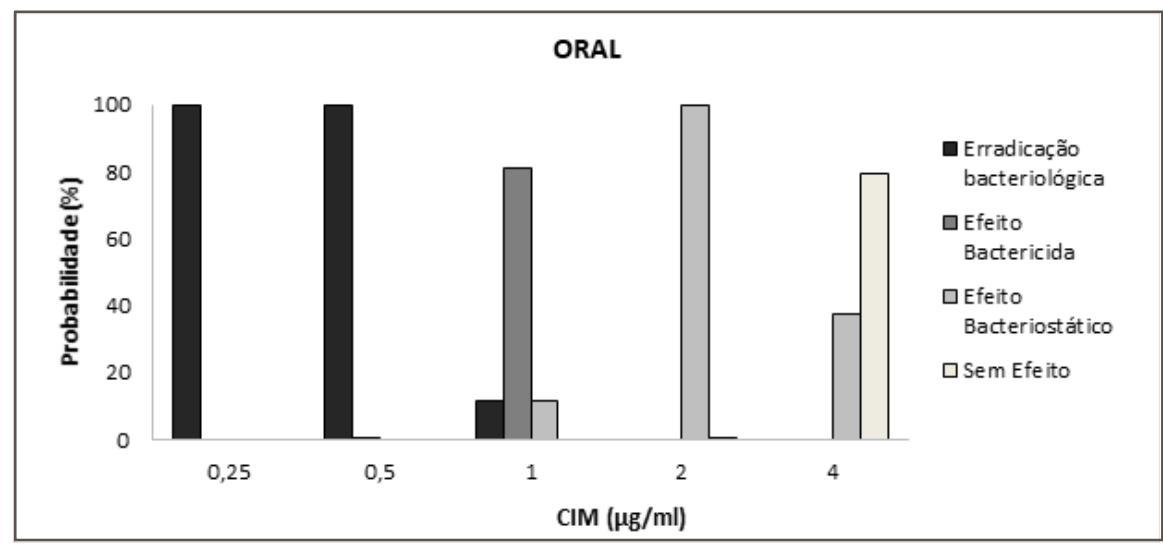

Figura 4: Probabilidade de atingir o índice ASC24/CIM de acordo com a CIM após tratamento com $22 \mathrm{mg} / \mathrm{kg}$ de florfenicol em equinos por via oral baseado na simulação de Monte Carlo $(n=10.000)$.

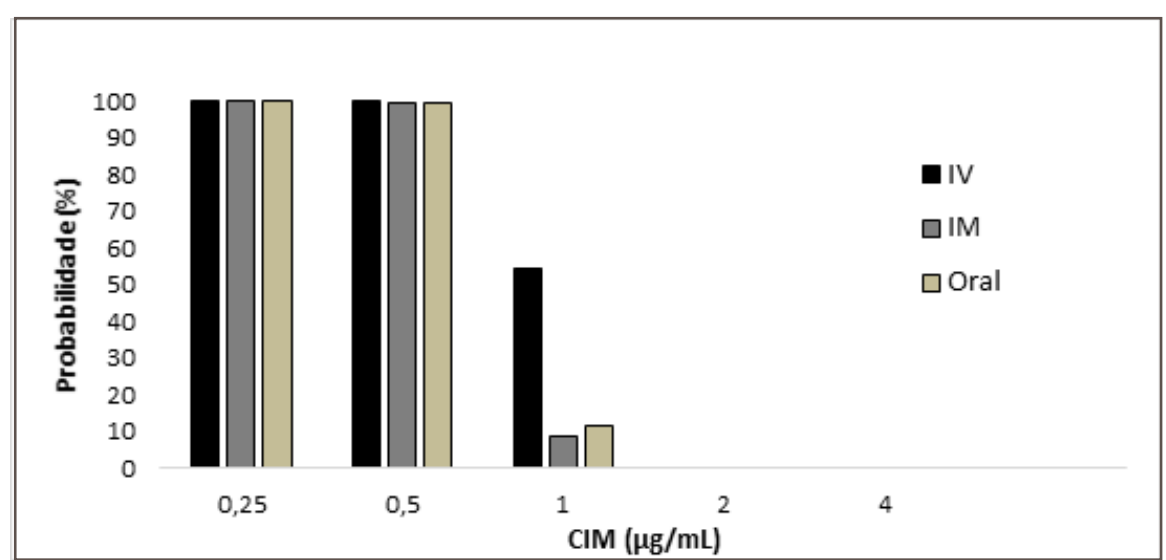

Figura 5: Probabilidade de atingir o índice ASC24/CIM correspondente à erradicação bacteriológica após o tratamento com $22 \mathrm{mg} / \mathrm{kg}$ de florfenicol via intravenosa (IV), intramuscular (IM) e oral em equinos baseado na simulação de Monte Carlo $(n=10.000)$.

para a metodologia de estudo e as conclusões alcançadas, como os dados da distribuição de CIM muitas vezes escassos e essa suscetibilidade bacteriana ser variável entre os isolados de uma região, logo é necessário um ponto de corte epidemiológico para as bactérias infectantes do rebanho equino brasileiro, neste caso principalmente para S. equi subsp. equi, patógeno responsável por uma doença altamente contagiosa causadora de graves prejuízos econômicos (KIRINUS et al., 2011).

$\mathrm{Na}$ susceptibilidade apresentada no estudo de Jacks et al. (2003) para o florfenicol e outros antimicrobianos in vitro frente às bactérias patogênicas do sistema respiratório de equinos, como os Streptococcus beta-hemolítico do grupo C, no qual Streptococcus equi subsp. equi está incluso, as $\mathrm{CIM}_{50}$ e $\mathrm{CIM}_{90}$ obtiveram valores desde inferior ou igual a $1 \mu \mathrm{g} / \mathrm{mL}$ a $2 \mu \mathrm{g} / \mathrm{mL}$. A partir disso, este trabalho demonstra que a eficácia do florfenicol não é suficiente na dose de $22 \mathrm{mg} / \mathrm{kg}$, principalmente, quando se considera CIMs superiores e a administração pelas vias intramuscular e oral (Figura 5). Isso deixa em evidência a necessidade de estudos epidemiológicos de suscetibilidade do florfenicol para patógenos dos rebanhos equinos brasileiros, assim como estudos das doses já preconizadas para a espécie, a fim de garantir um ajuste e, consequentemente, o sucesso terapêutico e a diminuição da resistência antimicrobiana.

O florfenicol é um derivado do cloranfenicol, que possui largo espectro de ação, além de ter boa capacidade de distribuição pelos tecidos. Comumente é considerado de efeito bacteriostático, contudo, trabalhos com modelagem PK/PD mostram que de acordo com os índices $\mathrm{ASC}_{24} / \mathrm{CIM}_{90}$ alcançados a ação pode ser desde bacteriostática, bactericida ou ainda de erradicação bacteriológica (DOREY et al., 2017).

Embora saiba-se que tradicionalmente a penicilina $\mathrm{G}$ é o antibiótico de eleição para a terapia contra a adenite equina, já que os estreptococos são frequentemente sensíveis a este antimicrobiano, com o uso crescente e indiscriminado de antibióticos, a utilização de subdoses e a falha na identificação do agente etiológico, poderia fazer com que esses microrganismos se tornassem resistentes às doses terapêuticas descritas. Em um estudo feito por Kirinus et al. (2011), mostra que o perfil fenotípico e de sensibilidade antimicrobiana do $S$. equi da região Sul do Brasil, traçado a partir de 38 isolados analisados, apenas alguns antibióticos obtiveram sensibilidade de $100 \%$ a bactéria, entre eles estão a penicilina, o cloranfenicol, a azitromicina, a cefalexina e a lincomicina. Alguns desses são considerados antimicrobianos de "máxima prioridade" na 
lista de antibióticos críticos para uso em humanos, segundo a Organização Mundial de Saúde (OMS), logo, são de última escolha na medicina veterinária, priorizando seu uso na medicina humana (WHO, 2017).

Neste contexto, a terapia antimicrobiana veterinária com os anfenicóis, entre eles o florfenicol, deve ser a primeira escolha indicando-os prioritariamente antes dos antibióticos de máxima prioridade, mas por conta da desatualização das doses tradicionalmente usadas e dos valores de CIM atuais, muitas vezes extrapolados das literaturas de outros países ou regiões, há um risco de falha na eficácia, fazendo com que recorrentemente àqueles antibióticos que deveriam ser utilizados em última instância, tornam-se habituais. Por isso é essencial que se conheça o perfil epidemiológico de CIM, otimizando as doses dos fármacos para o uso racional de antibióticos, evitando a cronicidade ou recorrência da doença, além do surgimento de resistência antimicrobiana.

\section{Conclusão}

Através deste estudo determinou-se que o efeito de erradicação bacteriológica, considerando a dose de $22 \mathrm{mg} / \mathrm{kg}$ pelas diferentes vias intravenosa, intramuscular e oral para o tratamento de adenite equina causada por $S$. equi. subsp. equi em equinos, têm altas taxas de eficácia frente a bactérias com CIM de até $0,5 \mu \mathrm{g} / \mathrm{mL}$, no entanto, considerando a via intravenosa, a antibioticoterapia atinge CIMs maiores, de 2 a $4 \mu \mathrm{g} / \mathrm{mL}$ com efeito bacteriostático, enquanto que as vias intramuscular e oral chegam a CIM de $1 \mu \mathrm{g} /$ $\mathrm{mL}$, apresentando efeito bactericida. Em suma, para o tratamento de infecções por microrganismos com CIMs superiores a essas simuladas, é imprescindível o ajuste da dose farmacológica, atentando-se para a via de administração realizada, conforme o efeito estabelecido, além disso, são necessários estudos de susceptibilidade bacteriana dos patógenos isolados em casos clínicos brasileiros para estimar o protocolo terapêutico ideal, evitando a resistência antimicrobiana.

\section{Agradecimentos}

A Coordenação de Aperfeiçoamento de Pessoal de Nível Superior (CAPES). A Conselho Nacional de Desenvolvimento Científico e Tecnológico - CNPq (424658/2016-0;313757/2019-4) (Edital PRP Nº5/2020 - PIBIC/CNPq). A Fundação de Amparo à Pesquisa do Estado de Minas Gerais - FAPEMIG (APQ-00780-19 e PPM-00691-17). Ao Complexo Multiusuário de Bioeficiência e Sustentabilidade da Pecuária da EMBRAPA e à Central de Análise e Prospecção Química (CAPQ) da Universidade Federal de Lavras (UFLA).

\section{Referências}

AHMAD, I.; HUANG, L.; HAO, H.; SANDERS, P.; YUAN, Z. Application of PK/PD Modeling in Veterinary Field: Dose Optimization and Drug Resistance Prediction. BioMed Research International, vol. 2016, 12 p. 2016.

ALONSO, J.M.; ÁVILA, A.R.; BUENO, L.M.C.; HATAKA, A.; MACHADO, V.M.V.; ALVES, A.L.G.; WATANABE, M.J.; RODRIGUES, C.A.; BARBOSA, R.M.; HUSSNI, C.A. Cervical vertebral osteomyelitis secondary to Streptococcus equi infection in an adult horse-case report. Arquivo Brasileiro de Medicina Veterinária e Zootecnia, v. 71, n. 6, p. 2041-2048, 2019.

DOREY, L.; PELLIGAND, L.; CHENG, Z.; LEES, P. Pharmacokinetic/pharmacodynamics integration and modelling of florfenicol for the pig pneumonia pathogens Actinobacillus pleuropneumoniae and Pasteurella multocida. PLOS ONE, v. 12, n. 5, 2017. Disponível em: https://doi.org/10.1371/journal. pone.0177568. Acesso em: 07 fev. 2021.

EMA. European Medicines Agency. Guideline on the use of pharmacokinetics and pharmacodynamics in the development of antimicrobial medicinal products." Document EMA/ CHMP/594085/2015, 2016.

FERRANTE, M. Eficacia de florfenicol para el tratamiento de infecciones por Pasteurella multocida y Mannheimia haemolytica en llamas. ENCICLOPÉDIA BIOSFERA, v. 15, n. 28, 2018.

FLOCK, M.; FRYKBERG, L; SKÖLD, M.; GUSS, B.; FLOCK, J. Antiphagocytic function of an IgG glycosyl hydrolase from Streptococcus equi subsp. equi and its use as a vaccine component. Infection and immunity, v. 80, n. 8, p. 2914-2919, 2012.

GOMES, Y.A.; RECKZIEGEL, G.H.; BRITO, I.D.S.S.; SILVA, T.I.B da. Avaliação microbiológica e molecular do Streptococcus equi subespécie equi e fatores de risco associados à adenite equina em propriedades rurais da microrregião de Rio Branco, Acre, Brasil. Biota Amazônia. v. 9, n. 3, p. 61-63, 2019. Disponível em: <https://periodicos.unifap.br/index.php/biota/article/view/4436>. Acesso em: 09 fev. 2021.
IBGE. Instituto Brasileiro de Geografia e Estatística - Pesquisa da Pecuária Municipal 2019. Disponível em: <https://sidra.ibge. gov.br/pesquisa/ppm/quadros/brasil/2019>. Acesso em: 24 abr. 2021.

KIRINUS, J.K.; PÖTTER, L.; GRESSLER, L.T. Perfil fenotípico e susceptibilidade antimicrobiana de Streptococcus equi isolados de equinos da região Sul do Brasil. Pesquisa Veterinária Brasileira, v. 31, n. 3, p. 231-238, 2011.

LIBARDONI, F. Equinos portadores de Streptococcus equi subespécie equi: Prevalência, fatores de risco e caracterização de alelos seM. 2015. 85 f. Tese (Doutorado) - Centro de Ciências Rurais - Universidade Federal de Santa Maria, Santa Maria, 2015.

LUO, W.; CHEN, D.; WU, M.; LI, Z.; TAO, Y.; LIU, Q.; PAN, Y.; QU, W.; YUAN, Z.; XIE, S. Pharmacokinetics/Pharmacodynamics models of veterinary antimicrobial agents. Journal of veterinary Science, v. 20, n. 4, 2019.

MCKELLAR, Q.A; VARMA, K.J. Pharmacokinetics and tolerance of florfenicol in Equidae. Equine Veterinary Jornal, v.28, n. 3, p. 209-213, 1996.

MORAES, C.M.; VARGAS, A.P.C.; LEITE, F.P.L.; NOGUEIRA, E.W.; TURNES, C.G. Adenite equina: sua etiologia, diagnóstico e controle. Ciência Rural, v. 39, n. 6, p. 19441952, 2009. Disponível em: http://www.scielo.br/scielo. php?script=sci_arttext\&pid=S0103-84782009000600050>. Acesso em: 08 jan. 2021.

ODA, K. Development of software for antimicrobial PK/PD simulation incorporating Monte Carlo simulation based on Microsoft $@$ Office Excel. Journal of Pharmaceutical Health Care and Sciences, v. 37, n. 6, p. 335-344, 2011.

MARTÍN, B.S.; FRESNO, M.; CORNEJO, J.; GODOY, M.; IBARRA, R.; VIDAL, R.; ARANEDA, M.; ANADÓN, A.; LAPIERRE, L. Optimization of florfenicol dose against Piscirickettsia salmonis in Salmo salar through PK/PD studies, v. 14, n. 5, e0215174, 2019. 
SHARMA, V.D.; SINGLA, M.; CHAUDHARY, M.; KUMAR, M.; BHATNAGAR, A. et al. Dose optimization of ceftriaxonevancomycin combination using fractional inhibitory concentration kinetics in resistant bacteria. ADMET and DMPK, v. 4, n. 3, p. 241-260, 2016. Disponível em: <https://hrcak.srce.hr/167045>. Acesso em: 08 fev. 2021.

TOUTAIN, P.L.; PELLIGAND, L.; LEES, P.; BOUSQUET-MELOU, A.; FERRAN, A.A.; TURNIDGE, J.D. The pharmacokinetic/ pharmacodynamic paradigm for antimicrobial drugs in veterinary medicine: Recent advances and critical appraisal. Journal of Veterinary Pharmacology and Therapeutics, p. 1-29, 2020.

TRANG, M.; DUDLEY, MN.; BHAVNANI, SM. Use of Monte Carlo simulation and considerations for PK-PD targets to support antibacterial dose selection. Current Opinion in Pharmacology, v. 36 , p. $107-113,2017$
XIAO, X.; LAN, W.; ZHAO, Y.; LI, R.; LIU, Y.; LIU, J.; WANG, Z. In vivo Pharmacokinetic and Pharmacodynamic (PK/PD) Modeling and Establishment of the PK/PD Cutoff of Florfenicol against Pasteurella multocida in Ducks. Frontiers in microbiology, v. 11, p. 3321, 2021.

WEI, Y.; JINRU, J.; TINGTING, X.; CHAOQUN, Y.; JIAHENG, F.; PING, S.; YONGHONG, $X$. Determining optimal dosing regimen of oral administration of dicloxacillin using Monte Carlo simulation. Drug Design, Development and Therapy, v. 11, p. 1951-1956, 2017. Disponível em: http://dx.doi.org/10.2147/DDDT.S139632 . Acesso em: 08 jan. 2021.

WHO, 2017. Critically Important Antimicrobials for Human Medicine. (6th revision) World Health Organization Advisory Group on Integrated Surveillance of Antimicrobial Resistence (AGISAR), Geneva, Suíça. 